\title{
Commentary: herbal medication use continues
}

Keywords: herbal medicine, homeopathy, sleep, naturopathy, insomnia

\section{Commentary}

A recent review of the literature revealed the reportings of herbal medication use to be between $20-80 \%$ of the general population in the United States. This variation of incidence of herbal medicine use becomes more concerning given the unknown number taking herbal medicines along with prescribed medications. Furthermore, this situation occurs in the absence of a regulation system (i.e. only of exclusion) and evidence of effectiveness. Worldwide, use of herbal medications extends to alternative medicine practices of naturopathy, traditional Chinese medicine, and homeopathy. ${ }^{1}$ Food and drug regulation of herbal medications exists in some countries formerly, such as Spain and informally where it is considered a food additive such as the United States. Despite the widespread use, little regulation and varying degrees of monitoring, popularity of herbal medications ensues. The World Health Organization considers herbal medicines have a preventative or therapeutic benefit to one or more organs. The amount and type of herbal medications that are dangerous to patients with renal, hepatic, cardiovascular and endocrine disorders are of particular note-but investigations are lacking indicating the extent of this.

Sleep and herbal medication use has a history dating back to ancient times. Xanthic bases (caffeine) herbal medications as a stimulant often used for daytime sleepiness. ${ }^{2}$ Analeptic herbal medications such as rosemary and cinnamon are used for stimulation by the sleepy patient as well. The hypnotic qualities of kava kava, popular among the indigenous Bush people of Micronesia are widely used and popular worldwide as well. The sedative qualities of Lavender have inundated marketing efforts of pre-sleep items such as lavender pillow spray and candles. Furthermore, examples would result in long lists of substances, with all having the same outcome-no regulation, unknown long-term effects and the possibility of interaction with prescribed conditions.

In integrative medicine, efforts are made to consider common patient practices of herbal medication use. This recognition is not acceptance of the practice but rather careful medical practice (i.e., preventative medicine focuses). In Europe, efforts are made to develop a system to register use and practices of herbal medicine with the ultimate categorizations of effects by time course of three/six/twelve months. ${ }^{3}$ This focus begins to provide a classification of herbal medicine use that may include concurrent use of prescription medications. Case studies in this area of herbal medication use and prescription use in patients with Insomnia and other medical conditions have identified

\author{
Volume I Issue 4 - 2017
}

\author{
Kathy Sexton Radek \\ Department of Psychology, Elmhurst College, USA
}

Correspondence: Kathy Sexton-Radek, PhD, C BSM, Department of Psychology, Suburban Pulmonary and Sleep Associates, Elmhurst College, USA, Email ksrsleep@aol.com

Received: October 28, 2017 | Published: November 24, 2017

nephrotoxicity, dose-related kidney and abdominal problems. A more rigorous approach will help to identify interaction and toxic effects. This becomes important in cases of patients taking herbal medications for the common Sleep Disorder of Insomnia as the patient discomfort with this disorder is high which likely promulgates increased herbal medication amount and usage patterns.

The adage here is responsible approaches to patient interview and assessment necessitate asking about common practices such as Herbal medication usage. ${ }^{4}$ Patient may consider the herbal descriptor as natural remedies and therefore without harm to the body. Therefore, they may not consider presenting their herbal medication use to the Health Care professional. A question such as, "What all are you doing to take care of your Insomnia?" may help to open the necessary assessment of this area with our sleep patients.

\section{Acknowledgements}

None.

\section{Conflict of interest}

The author declares no conflict of interest.

\section{References}

1. Bent S, Padula A, Moore D, et al. Valerian for sleep: a systematic review and meta-analysis. Am J Med. 2006;119(12):1005-1012.

2. Devesa AJG, Martínez AM, Ortega-Albás JJ. Herbal drugs and sleep: What can we expect? Journal of Sleep Disorders \& Therapy. 2015;4:196.

3. Moreira DDL, Teixeira SS, Monteiro MH, et al. Traditional use and safety of herbal medicines. Brazilian Journal of Pharmacognosy. 2014;24(2):248-257.

4. Rivera J, Loya AM, Ceballos R. Use of herbal medicines and implications for Conventional drug therapy medical sciences. Alternative \& Integrative Medcine. 2013;2:130. 